\title{
The value of simulation debriefing in launching reduced anxiety and improved self-confidence in the clinical setting for accelerated baccalaureate nursing students
}

\author{
Debra R. Wallace*1, Jaya Mini Gill ${ }^{2}$ \\ ${ }^{1}$ School of Nursing at California State University of Northridge, United States \\ ${ }^{2}$ John Wayne Cancer Institute, United States
}

Received: November 22, 2018

Accepted: March 10, 2019

Online Published: March 25, 2019

DOI: $10.5430 /$ jnep.v9n7p31

URL: https://doi.org/10.5430/jnep.v9n7p31

\begin{abstract}
Background and objective: The development of self-confidence is an essential element of a nurse in the clinical setting. Nursing educators discuss the addition of simulation and debriefing into learning activities, which play a central role in identifying the fundamental elements of safety and clinical efficiency.

Methods: Quality and Safety Education for Nurses (QSEN) competencies are used to examine the data supporting the effectiveness of simulation debriefing in nursing students registered in a fast-tracked baccalaureate program. This novel approach allows one to quantitatively measure the relationship between simulation debriefing, self-confidence and reduced anxiety.

Results: Univariate Spearman Rho regression displays a significant positive correlation between reduced anxiety, self-confidence, and debriefing. The feedback received is encouraging, productive, and effective to learning. Logistic multivariate regression reveals debriefing mechanisms predict developing self-confidence and reducing anxiety, allowing the likeness on student's clinical judgement and methodology to patient care $\left(\chi^{2}=34.249, p=.011\right)$, sufficient time being provided to reflect and review clinical performance $\left(\chi^{2}=0.68, p=.30\right)$ and identifying the justification for the actions and responses $\left(\chi^{2}=119.365, p=.001\right)$.

Conclusions: Debriefing is a central element that can be applied as a teaching strategy during simulation. This study offers further understanding of the role of debriefing in enhancing self-confidence and reducing anxiety in nursing students. This is a critical learning component and ought to be applicably focused in nursing education.
\end{abstract}

Key Words: Simulation, Self-Confidence, Anxiety, Simulation Debriefing, Nursing students

\section{INTRODUCTION}

Self-confidence is an essential element in a nurse's ability to provide good patient care, as it is required to detect early changes in a patient's status so appropriate interventions can be implemented. Thus, when nursing students exude confidence in their own abilities, recipients of nursing care are ben- efited. Nurse educators must be cognizant of the framework which helps promote self-confidence in nursing students, as it will allow one to focus on the needs of their patients and become a safe and competent practitioner. In recent years, simulation has been used to reduce anxiety in nursing students. ${ }^{[1]}$ The use of simulation involves employing a lifelike

\footnotetext{
* Correspondence: Debra R. Wallace; Email: debra.wallace@ csun.edu; Address: School of Nursing at California State University of Northridge, United States.
} 
computerized mannequin which has the capability to act on real-world inputs to assess actions. ${ }^{[2]}$ It has been shown that simulation allows one to build self-confidence and develop competencies to help enable performance in a real-world setting. ${ }^{[3]}$ Simulation has been defined by other authors as an approach which allows an individual to not only acquire and employ the competencies to create real-life situations, but also receive feedback to help enhance their academic needs. ${ }^{[4]}$ Utilizing simulation allows students to increase their participation in learning activities. A study by Gore, Hunt, Parker and Raines (2011) shows how there is a level of reduced anxiety when carrying out a simulation, which in a traditional clinical setting is much difficult to execute. ${ }^{[5,6]}$

\subsection{Specific aims}

The purpose of this study is to investigate the association between simulation debriefing and decreased anxiety and increased self-confidence in the clinical setting. QSEN-based competencies are used for analysis amongst a study population of nursing students registered in a California State University fast-tracked baccalaureate program.

\subsection{Literature review}

Nursing education has been shown to provide the underlying basis fostering the learning structure for nursing students. ${ }^{[2]}$ A suggested learning approach to assist in connecting the gap between clinical experience and classroom knowledge is the use of patient simulation. It is an educational tool which allows one to evaluate a student's competence and aptitude. Simulation can be programmed to fit a student's level of proficiency as desired. ${ }^{[7]}$ As a result, the advantages to utilize simulation are numerous as it may decrease anxiety in clinical performance, and meet teamwork competencies for students. ${ }^{[3,6-10]}$ A study by Waznonis (2015) also found that simulation offers the opportunity to increase self-confidence in students. ${ }^{[11]}$ Previous studies are limited as they did not reflect on the working dynamics of simulation debriefing and its effects on decreasing anxiety.

The transition to a professional role from nursing school requires two significant components in healthcare, patient safety and applying critical thinking skills to make key decisions. Development of such components requires assistance from faculty in helping nursing students develop the skills. Patient safety is an essential component associated with quality nursing care as the health care system is prone to a risk of errors, which can potentially lead to unfavorable outcomes. Therefore, it is important for student nurses to learn from mistakes in an educational setting in order to develop strategies to prevent errors once hired in a clinical setting. ${ }^{[12]}$ Simulation allows for reflective learning, where one is able to review performance, and earn feedback from the facilitator by observing the students' clinical abilities. ${ }^{[10]}$ Additionally, the use of simulation allows for an interactive learning environment by requiring communication among team members and using standardized patients, which depict common issues experienced by nurses. ${ }^{[13]}$ Simulation amplifies real experiences as it allows students to reproduce their actions in the real world; thus allowing for a better focus on patient care. The entire simulation process includes preparation before hand as well as debriefing after the simulation concludes.

Debriefing has increased its integration into nursing education. A recent study involving pre-clinical students found debriefing allows one the opportunity to gain immediate feedback in areas encompassing performance and communication with their instructors. This in turn allows for the development of self-directed adult-learning habits. ${ }^{[14]}$ Prior studies have investigated the role of simulation in nursing students both with and without debriefing sessions. One study found that in areas of clinical performance, self-confidence, and overall satisfaction with the simulation experience, students in the simulation-debriefing group scored higher and experienced reduced anxiety and improved competency. ${ }^{[15]}$ Another study observed the effectiveness of debriefing on improving clinical reasoning skills in a concept termed Meaningful Learning and found a positive correlation amongst a participants' discernment of high-quality debriefing and clinical reasoning. ${ }^{[16]}$ While the advantages of debriefing demonstrate growth, its importance to reduced anxiety continues to be indeterminate. ${ }^{[17]}$

\subsection{Debriefing}

The debriefing process is a learning method used during simulation, aimed at promoting reflective thinking to assist in the evaluation and use of critical thinking skills. Reflection is a strategy known to solidify learning. ${ }^{[18]}$ Debriefing includes reflective thinking and verbal responses by students, allowing them to be engaged in their learning. ${ }^{[16]}$ Additionally, the use of debriefing gives students the opportunity to verbally discuss and evaluate their actions in a given scenario. ${ }^{[19]}$ Organizing debriefing sessions into small groups may result in more repetitive training, which is understood to be essential for being proficient in simulation exercises. Reflection is an educational strategy used to involve one's rational with experiences and to gain knowledge from such experiences. Debriefing helps to review key concepts, assess reasoning to interventions, achieve a more comprehensive perception of knowledge, and maintain the competencies for future use. Effective debriefing occurs when the partakers carry out most of the discussion. The role of the facilitator is to create an environment for students which is protected for learning and 
arranged as a free learning event. ${ }^{[20]}$ These approaches can be applied to distinguish certain deficits and offer remediation for warranting safe practice. The gap remaining among debriefing and critical thinking skills in simulation is unclear, and has not yet been studied to date. Having such information available is imperative for targeting efforts to enhance education and practice.

\subsection{Anxiety}

When new graduate nurses begin their professional careers in the acute care setting, sentinel events are likely to occur. ${ }^{[21]}$ Nursing education must occur in both the classroom and in clinical areas, as it is a practice discipline. Students must be able to apply the information acquired, carry out the required competencies, and integrate the behaviors necessary in nursing.

Various scholars have attempted to describe the unessential features of anxiety. Merriam-Webster, 2011 defines anxiety as an uneasy or painful mind usually over a forthcoming ill, a apprehensive concern or awareness, and an aberrant and great sense of fear and uneasiness often discernable by physiological signs (as sweating, tension, and increased pulse). Anxiety also involves a doubt concerning the reality and nature of the threat, and by self-doubt about one's capacity to cope with it. ${ }^{[22]}$ Others define anxiety as the psychophysiological indicator that the stress reaction has commenced. ${ }^{[23]}$ Stress is normal and can be a motivator for individuals to take action. However, stress in increased levels can be unsafe, leading to physical symptoms including pain, light-headedness, headaches, muscle tension, sweating, and decreased attentiveness. ${ }^{[24]}$ By assisting students in managing anxiety during simulation, instructors are showing nursing students how to provide better care. The simulation extends the stress of a "real" patient care setting, without the risk of harming an actual patient. Displaying concern for students facing anxiety also underlines the compassionate nature of nursing. The application of simulated clinical experiences is central to the outcome of using skills to decrease anxiety, ${ }^{[25]}$ but there is limited research to measure its helpfulness of this learning.

\subsection{The adult learning model for reducing anxiety and developing self-confidence skills}

The theory of andragogy by Malcolm Knowles' in 1984 inspires educationalists to reflect on other theories as frameworks for simulation. ${ }^{[26]}$ For example, Brookfield describes reflection, which Clapper deems is a valuable skill for both learners and instructors, as when one "receives regular feedback from students on what is working in the classroom and what is not."[27] The effect of stress on learning, as Clapper Published by Sciedu Press describes it, is "an emotional thing." It is a positive emotion which forges the path for memory and higher-order thought as the brain is vulnerable to emotion. The negative effects on learning can come from a sense of apprehension and a notable question arises: how much stress is too much? Being "unveiled as a fraud" is another stressful concern which may arise from some participants in simulation. ${ }^{[27]}$ Clapper proposes that while the experience in simulation may perhaps induce negative emotions, it is important to discuss such emotions in the debriefing process post-simulation, and could aid learners in making meaning of the experience. ${ }^{[27]}$ The different theories by Knowles' including adult learning theory, social construct theory or constructivism, reflective practice, and novice to expert theory were also examined. Other authors have expressed that one must define the purpose of a simulation, and whether it is for teaching or learning. If the intent is perceived from a learning model, it is suggested that social construct theories are highly favorable as a framework for the design. ${ }^{[28]}$ A study by Wallace and Boller (2014) has presented that rubrics direct one to concentrate on fundamental regions consisting of skill training, offering an approach to verify the progress of the training in learners and mentors. ${ }^{[29]}$ As newly graduate RNs gain more experience, rubrics offer a channel to concentrate on key abilities which may be present at various levels of skill presentation.

\section{METHODOLOGY}

\subsection{Setting and participants}

The teaching methodology used in the simulation debriefing application is an accepted element with well-defined learning aims and outcomes. As preparation for the medical surgical rotation, it is obligatory for nursing students in their first two semesters to participate in the simulation debriefing. The simulation exercises involved three participants in each group. In each simulation, participants play different positions, thus allowing them to learn the responsibility and roles of all team members. Additionally, during the simulation, students were given the opportunity to request any mandatory source documents including simulated paperwork, blood results, and an electrocardiogram (ECG) tracing. Skill stations, such as peripheral intravenous access and foley catheter insertion, were also available for students to practice and improve their level of confidence. Once all simulations were completed, a focus group was conducted for a structured facilitated debriefing session. Participants were requested to answer the subsequent questions: (1) When the nurse was somewhat concerned, what could the nurse have done? (2) What action from the initial symptom would have brought action to patient care? Is there anything else of concern? Physiologically, was there anything of significance to note? (3) Did 
something take you by disbelief? This survey encouraged learners to participate in this debriefing session. It allowed students to practice communication, and professional behavior and reflective skills. It also allowed observers to use positive communication to increase confidence. For faculty, this activity provided insight as to how integrating simulation into nursing education will show how students may approach situations in the clinical setting.

\subsection{Data collection}

Data were collected on the expected learner actions likely to occur during simulation using a list comprising of case flow description. Analysis on the effects of simulation on helping students develop stronger cognitive skills and clinical competencies was evaluated using the Simulation Evaluation Survey. Face validity was established after the rubric was evaluated by a group of content experts for relevance and transparency. Evaluating the content validity is essential to justify performance indicators and descriptors. ${ }^{[29]}$ To maintain consistency, one investigator was assigned the role of rating all debriefing performances extending from 1, disagreeto 4 , agree-strongly using a grading rubric. Students were asked to rate critical thinking using a Likert scale, to answer how they believe simulation contributed to developing clinical skills.

\subsection{Ethical consideration}

Ethical approval was obtained from the Institutional Review Board (IRB) prior to implementing the study. As part of the course curriculum, an end of semester evaluation of students was done. All subjects were informed that their participation was completely voluntary in filling out the simulation evaluation questionnaire and would not affect their performance in the course. In addition, confidentiality of all participants was maintained as all questionnaires remained anonymous.

\subsection{Data analysis}

The Statistical Package for the Social Sciences (SPSS) 22.0 for Windows was used to analyze the data. In this study, expectations were met for logistic regression, which includes size of sample, multicollinearity, and independence from outliers and inaccuracies. Vittinghoff and McCulloch (2007) suggest an adequate number for predicting logistic regression is 10 subjects. ${ }^{[30]}$ Thus, 205 subjects were included in this model for the five predictors of debriefing. A sample number of 205 is thus considered to be sufficient for the five debriefing predictors comprised in the model.

The bivariate correlation was surveyed amongst reduced anxiety, self-confidence, and the various debriefing components. Spearman Rho correlation was performed on the collected data. Furthermore, multicollinearity was evaluated using the different debriefing components by calculating the correlations. A bivariate correlation of 0.7 or greater implies multicollinearity. The results seen on Table 1 with values less than 0.7 reveal a correlation between the different components of debriefing including 1) student's reflecting clinically on the judgement and methodology to patient care; 2) received response being encouraging and productive; 3 ) feedback effective to learning; 4) debriefing time needed to reflect and review performance was appropriate; and 5) no multicollinearity was shown validation to reactions to such performances (see Table 1).

Table 1. Correlation matrix of study independent variables

\begin{tabular}{lllll}
\hline & $\begin{array}{l}\text { Debriefing \& reflection on } \\
\text { clinical judgment \& } \\
\text { methodology to patient care }\end{array}$ & $\begin{array}{l}\text { Debriefing feedback } \\
\text { was encouraging \& } \\
\text { productive }\end{array}$ & $\begin{array}{l}\text { Debriefing feedback } \\
\text { was effective to } \\
\text { learning }\end{array}$ & $\begin{array}{l}\text { Sufficient debriefing } \\
\text { time to review } \\
\text { performance }\end{array}$ \\
\hline $\begin{array}{l}\text { Debriefing feedback was } \\
\text { encouraging \& productive }\end{array}$ & .666 & & & \\
Debriefing feedback & $.000^{*}$ & .620 & .836 & \\
effective to learning & $.000^{*}$ & $.000^{*}$ & .648 & $.000^{*}$ \\
Sufficient debriefing time & .516 & .599 & .605 & .592 \\
to review performance & $.000^{*}$ & $.000^{*}$ & $.000^{*}$ & $.000^{*}$ \\
Debriefing helped identify & .529 & .587 & & \\
action justification & $.000^{*}$ & $.000^{*}$ & &
\end{tabular}

\section{RESUlts}

The analysis of the unadjusted bivariate correlation was found to be positively significant between critical thinking and all facets of debriefing (see Table 2). With the 205 students, $95 \%(\mathrm{~N}=195)$ concluded that simulation enhanced self-confidence. Statistical significance was seen in some debriefing components in the logistic regression model, implicating that the model could distinguish between subjects who concurred and those who did not believe that simulation enriched their anxiety and self-confidence. Table 3 shows 
the significant influence amongst three of the five debriefing components: allowing reflection on student's clinical judgement and methodology to patient care $\left(\chi^{2}=34.249, p=\right.$ .011); sufficient debriefing time given to reflect and review clinical performance $\left(\chi^{2}=.068, p=.030\right)$; and assisting in the justification for the actions and responses to performances $\left(\chi^{2}=119.365, p=.001\right)$. There was no statistical significance to debriefing and the independent variable of critical thinking in areas defining debriefing as "encouraging and productive" and "feedback effective to learning".

Table 2. The effect of critical thinking \& debriefing components on bivariate spearman Rho correlation

\begin{tabular}{llc}
\hline Self Confidence & Correlation & $\boldsymbol{p}$-value \\
\hline Debriefing \& reflection on clinical judgment \& methodology to patient care & .266 & $.000^{*}$ \\
Debriefing feedback was encouraging \& productive & .242 & $.001^{*}$ \\
Debriefing feedback effective to learning & .240 & $.001^{*}$ \\
Sufficient debriefing time to review performance & .201 & $.004^{*}$ \\
Debriefing helped identify action justification & .342 & $.000^{*}$ \\
\hline
\end{tabular}
${ }^{*} p \leq .05$

Table 3. Significance, odds ratio, and CI for critical thinking and debriefing

\begin{tabular}{lllll}
\hline \multirow{2}{*}{ Variable } & \multirow{2}{*}{ Sig } & Odds & \multicolumn{2}{c}{ 95\% CI for Odds Ratio } \\
\cline { 3 - 5 } & & Ratio & Lower & Upper \\
\hline Debriefing \& reflection on clinical judgment \& methodology to patient care & $.011^{*}$ & 34.249 & 2.245 & 522.437 \\
Debriefing feedback was encouraging \& productive & .123 & .109 & .006 & 1.826 \\
Debriefing feedback was effective to learning & .220 & 5.965 & .343 & 103.708 \\
Sufficient debriefing time to review performance & $.030^{*}$ & .068 & .006 & .769 \\
Debriefing helped identify action justification & $.001^{*}$ & 119.365 & 7.469 & 1907.635 \\
\hline
\end{tabular}
${ }^{*} p \leq .05$

\section{Discussion}

\subsection{Study limitations}

Limitations of the study are an important component of consideration. The sample size recruited for this study was small and from a single institution. Therefore, vigilance should be taken when interpreting the results. Moreover, the findings of this study are limited, as results cannot be generalized to all nursing students because the sample size was small. With the small sample size, it can limit the conclusions which can be drawn, as there was near significant outcomes of the study variables such as advanced cognitive competencies. Therefore, a larger sample size needs to be utilized in quantitative and qualitative studies to determine if simulation is an effective method in enhancing these important attributes. Additionally, using a broader sample population, such as nursing students at different institutions and those who are in distinct levels within the nursing program, would permit for more comprehensive evaluation of the effects of simulation.

\subsection{Recommendations}

Results of the study demonstrate that simulation debriefing holds implications aimed at further research, examining the correlation between self-confidence, decreased anxiety, clinical judgment, and direct patient care outcomes. It has always

Published by Sciedu Press been a challenge for nursing instructors to prepare competent nurses who have the ability to think critically and contribute to positive patient outcomes. Thus, the knowledge gained from this study will allow nursing instructors to interpret such variables, along with understanding how debriefing is an essential component in simulation. Simulation debriefing allows one to develop the skills essential to nursing which include self-confidence, competency, problem solving, and critical thinking skills. Furthermore, outcomes from the quantitative study show that applying patient simulation has an impact on self-confidence abilities. Prospective research may possibly use data from our student surveys in turn to analyze quantitative data, fund greater demographics, and use valuable and dependable tools.

\section{BIOS STATEMENT}

Debra Wallace, DNP, APRN, FNP-BC, serves as part time faculty in the School of Nursing at California State University of Northridge and mentors nursing students at Cal State University of Northridge and nurse practitioner students while working for Kaiser Permanente in Santa Clarita, CA.

Dr. Jaya Gill earned her Bachelor of Science in Biology from UCLA in 2006. In 2011, she earned her MD degree from American University of the Caribbean, and in 2014 earned 
a Bachelor of Science in Nursing degree from CSUN. She has nearly 3 years of orthopedics research experience at the UCLA biomechanics research division, and was an associate editor for the Journal of Biomechanics and an editorial reviewer for a variety of journals. She has worked as a critical care registered nurse at Providence Saint John's Health Center, gaining invaluable experience in acute care nursing. Currently, she is involved in clinical trial processes in the

\section{REFERENCES}

[1] Hollenbach P. Simulation and its effect on anxiety in baccalaureate nursing students. Nursing Education Perspectives. 2016; 37(1): 45-47.

[2] Nuraini T, Afifah E, Agustini N, et al. Human patient simulation to improve the attitude of the nursing students. Journal of Nursing Education and Practice. 2015; 5(4): 52-57. https ://doi .org/10 .5430/jnep.v5n4p52

[3] Kirkham L. Exploring the Use of High-Fidelity Simulation Training to Enhance Clinical Skills. Nursing Standard. 2018; 32: 44-53. PMid:29411953 https://doi.org/10.7748/ns.2018.e10693

[4] Wallace D, Moughrabi S. The effectiveness of simulation in advancing quality and safety education for nurses-based competency in accelerated nursing students. Journal of Nursing Education and Practice. 2015; 5(8): 17-25. https://doi.org/10.5430/jnep.v5n8p17

[5] Gore TG, Hunt CW, Parker F, et al. The Effects of Simulated Clinical Experiences on Anxiety: Nursing Students' Perspectives. Clinical Simulation in Nursing. 2011; 7(5): e175-e180.

[6] Szpak JL, Kameg KM. Simulation Decreases Nursing Student Anxiety Prior to Communication with Mentally Ill Patients. Clinical Simulation in Nursing. 2013; 9(1): e13-e19. https : //doi.org/10 $.1016 / j$.ecns. 2011.07.003

[7] Solnick A. High fidelity simulation in nursing education: A review of the literature. Clinical Simulation in Nursing. 2007; 3(1): e41-e45. https://doi.org/10.1016/j.ecns. 2009.05.039

[8] Arwood E, Kaakinen J. Simulation based on language and learning (SIMBaLL): The model. International Journal of Nursing Education Scholarship. 2009; 6(1).

[9] Creswell JW, Clark VLP. Designing and Conducting Mixed Methods Research. 4th ed. Sage Publishing; 2013.

[10] Wallace D, Moughrabi S. The efficacy of simulation debriefing in developing critical thinking in accelerated baccalaureate nursing students. Journal of Nursing Education and Practice. 2016; 6(5): 13-18 https://doi.org/10.5430/jnep.v6n5p13

[11] Waznonis AR. Simulation Debriefing Practices in Traditional Baccalaureate Nursing Programs: National Survey Results. Clinical Simulation in Nursing. 2015; 11: 110-119. https : //doi .org/10 $.1016 / j$.ecns. 2014.10.002

[12] Dillard N, Sideras S, Ryan M, et al. A collaborative project to apply and evaluate the clinical judgment model through simulation. Nursing Education Perspectives. 2009; 30(2): 99-104.

[13] Aebersold M, Tschannen D. Simulation in Nursing Practice: The Impact on Patient Care. OJIN: The Online Journal of Issues in Nursing. 2013; 18(2).

[14] Ali L, Nisar S, Ghassan A. Role of debriefing as a learning tool in simulation based learning for students of preclinical years at the end of
Department of Translational Neurosciences and Neurotherapeutics at the John Wayne Cancer Institute. She coordinates the maintenance of federally regulated clinical research studies including the implementation of protocol treatment, care, management, and follow-up of patients enrolled on highly complex research studies.

\section{CONFLicts OF InTEREST Disclosure}

The authors declare that there is no conflict of interest. two consecutive modules-initial experience. Journal of Ayub Medical College of Abbottabad. 2015; 27(2): 425-429. PMid:26411133

[15] Rayoo EN, Ha EH. The importance of debriefing in simulation-based learning: comparison between debriefing and no debriefing. Computer Informatics Nursing. 2015; 33(12): 538-545. PMid:26587701 https://doi.org/10.1097/CIN. 0000000000000194

[16] Dreifuerst KT. Using Debriefing for Meaningful Learning to Foster Development of Clinical Reasoning in Simulation. Journal of Nursing Education. 2012; 51(6): 326-333. PMid:22495923 https: //doi.org/10.3928/01484834-20120409-02

[17] Nielson B, Harder N. Causes of student anxiety during simulation: What the literature says. International Nursing Association for Clinical Simulation and Learning. 2013; 9(11): e507-e512. https://doi.org/10.1016/j.ecns. 2013.03.003

[18] Craft M. Reflective writing and nursing education. Journal of Nursing Education. 2005; 44: 53-57. PMid:15719711

[19] Tosterud R, Petzäll K, Hedelin B, et al. Psychometric Testing of the Norwegian Version of the Questionnaire, Student Satisfaction and Self-confidence in Learning, Used in Simulation. Nurse Education in Practice. 2014; 14(6): 704-708. PMid:25458231 https: //doi.org/10.1016/j.nepr.2014.10.004

[20] Billings DM, Halstead JA. Teaching in nursing a guide for faculty. 4th ed. St. Louis, Missouri: Saunders Elsevier; 2012.

[21] Strouse AC. Multidisciplinary simulation centers: Promoting safe practice. Clinical Simulation in Nursing. 2010; 6(4): e139-e142. https://doi.org/10.1016/j.ecns.2009.08.007

[22] “anxiety." Merriam-Webster.com. 2011. Available from: https: //www.merriam-webster.com

[23] Shin LM, Liberzon I. The Neurocircuitry of Fear, Stress, and Anxiety Disorders. Neuropsychopharmacology. 2010; 35(1): 169-91. PMid: 19625997

[24] Available from: http://www.webmd.com/balance/stress-m anagement/stress-symptoms-effects_of-stress-on-the -body\#1\T1\textquotedblleftStressManagementHealthC enter \T1\textquotedblright WebMD.com. 2017. WebMD, LLC. Web. 02 May 2017.

[25] Gore T, Hunt CW, Parker F, et al. The effects of simulated clinical experiences on anxiety: Nursing students' perspectives. Clinical Simulation in Nursing. 2011; 7: e175-e180.

[26] Knowles MS, Holton EF, Swanson RS. The adult learner. 6th ed. Burlington MA: Elsevier; 2005

[27] Clapper TC. Beyond Knowles: What those conducting simulation need to know about adult learning theory. Clinical Simulation in Nursing. 2010; 6(1): e7-e14. https://doi.org/10.1016/j.ec ns.2009.07.003 
[28] Kaakinen J, Arwood E. Systematic review of nursing simulation literature for use of learning theory. International Journal of Nursing Education Scholarship. 2009; 6(1).

[29] Wallace D, Boller J. New nurse practitioner competencies: Skill development and reflective writing rubrics. Journal for Nurse Practi- tioners. 2014; 10(7): e13-e21. https://doi.org/10.1016/j.nu rpra.2014.04.018

[30] Vittinghoff E, McCulloch C. Relaxing the rule of ten events per variable in logistic and cox regression. American Journal of Epidemiology. 2007; 165(6): 710-718. PMid:17182981 https://doi .org/ 10.1093/aje/kwk052 